\title{
Morphological and Mechanical Stability of HCP-based Multilayer Nanofilms at Elevated Temperatures
}

\author{
Y.Y. Lu ${ }^{1}$, R. Kotoka ${ }^{2}$, J. P. Ligda ${ }^{3}$, S. N. Yarmolenko ${ }^{2}$, B. E. Schuster ${ }^{3}$ and Q. Wei ${ }^{1^{*}}$ \\ ${ }^{1}$ Department of Mechanical Engineering, The University of North Carolina at Charlotte, Charlotte, NC \\ 28223-0001, USA. \\ ${ }^{2}$ Department of Mechanical Engineering, NC A\&T State University, Greensboro, NC 27411, USA. \\ ${ }^{3}$ WMRD, US Army Research Laboratory, Aberdeen Proving Ground, Aberdeen, MD 21005, USA. \\ A manuscript submitted to Surface and Coatings Technology for consideration of publication
}

*Corresponding Author: (704) 6878213 (tel); (704) 6878345 (fax); email: qwei@,uncc.edu (Q. Wei) 


\begin{abstract}
The thermal stability of $\mathrm{Mg} / \mathrm{Ti}$ multilayer nanofilms was investigated by examining their microstructure and nanoindentation hardness after annealing at various temperatures and time periods. The multilayers with individual layer thickness $h \geq 5 \mathrm{~nm}$ exhibit excellent capability of maintaining the lamellar microstructure and high strength up to $200{ }^{\circ} \mathrm{C}$ for annealing time up to 2.0 hours. The annealed multilayer films with $h=2.5 \mathrm{~nm}$ are still highly textured but characterized with discontinuous layer interfaces, in which the transition of atomic arrangement from hexagonal close-packed (HCP) to body-centered cubic (BCC) structure was observed at columnar boundaries. The degradation of uniform lamellar microstructure is related to the decrease of hardness with annealing temperature at this size scale. A diffusion based instability mechanism was proposed for this typical HCP-based nanoscale multilayer system.
\end{abstract}

Key words: Metallic multilayer; thermal stability; microstructure; nanoindentation hardness. 


\section{Introduction}

Multilayered metallic films exhibit great potentials in engineering applications because of their impressive strength, ductility, wear and corrosion resistance. Over past decades, the deformation behavior and strengthening mechanisms of the multilayered metallic films have been widely explored [1-4]. For example, it has been found that the strength of most metallic multilayers can be remarkably improved by reducing the individual layer thickness to submicron level or even less [5]. In contrast, the thermal stability, which is an essential property to be considered in industrial environment, has not received enough attention.

Most frequently, the heating treatments on metallic multilayers were intentionally performed to trigger specific reactions between the original elements while the intermetallic or amorphous product would serve as a final constituent $[6,7]$. For example, Weihs and coworkers used highly pure $\mathrm{Cu}$ and $\mathrm{Zr}$ to prepare $\mathrm{Cu}$ /amorphous $\mathrm{Cu}-\mathrm{Zr}$ and $\mathrm{Cu} / \mathrm{Cu}_{51} \mathrm{Zr}_{14}$ multilayers by monitoring the heating temperature of differential scanning calorimetry (DSC) [8]. However, the unexpected formation of new phases is generally deemed as an evidence of poor thermal stability because they are likely to bring about the disintegration of lamellar microstructure and degeneration of mechanical performance $[9,10]$. Moreover, the inter-diffusion that is present in many miscible multilayer systems at elevated temperatures could also cause above problems and therefore impair the thermal stability [11-14]. A study from Kucharska et al. revealed serious surface discontinuities in the $\mathrm{Cu}(2 \mathrm{~nm}) / \mathrm{Ni}(1.8 \mathrm{~nm})$ multilayer specimens annealed at $220{ }^{\circ} \mathrm{C}$. With a further increase in temperature, intensive delamination of the multilayer sample from the silicon substrate ensued [13].

For polycrystalline metallic multilayers, the grain growth within the layers always takes place as the temperature increases [15]. It has been found that the hardness of electrodeposited 
$\mathrm{Cu} / \mathrm{Ag}$ multilayer films drops significantly after a $150^{\circ} \mathrm{C}$ annealing due to the spheroidization of grains [16]. Similarly, coarsening of in-plane grain size and resultant strength loss have been observed in $\mathrm{Ni} / \mathrm{Ru}$ multilayers with comparatively large periodicity $(>36 \mathrm{~nm})$ during annealing [17]. Misra et al., however, claimed that the multilayer spheroidization and pinch-off are more likely to occur in the annealed $\mathrm{Cu} / \mathrm{Nb}$ multilayers with small individual layer thickness $(h, \sim 15$ $\mathrm{nm}$ ), compared to those with $h \geq 35 \mathrm{~nm}[18,19]$. They attributed the excellent thermal stability of films containing thicker $\mathrm{Cu}$ and $\mathrm{Nb}$ layers (up to $700{ }^{\circ} \mathrm{C}$ ) to the development of zig-zag alignment of triple junctions which stabilizes the lamellar microstructure effectively. In this sense, the effect of heating on the morphological stability of metallic multilayers is much more complex than expected. Consider the change of mechanical properties described above as well as the possible alternation of magnetic, optical and electrical properties with the rising temperature [20-23], more efforts on the investigation of thermal stability in metallic multilayers are needed.

In this paper we focus on the thermal stability of hexagonal close-packed (HCP)-based metallic multilayers which have distinct deformation modes from those made up of cubic metals. To the best of our knowledge, the vast majority of such research efforts in the literature has been focused on cubic systems. The work of $\mathrm{Lu}$ and co-workers appears to be the first in examining the microstructure and mechanical properties of multilayer systems made of HCP metals [24]. However, no efforts can be identified in the literature on the thermal stability of nanoscale multilayer systems made of HCP metals. Therefore, in this work, a series of annealing processes will be carried out on the $\mathrm{Mg} / \mathrm{Ti}$ multilayered films with various individual layer thicknesses. Annealing will be performed at various temperatures for various lengths of time. Thermal stability of the HCP multilayer specimens will be evaluated in terms of crystallography, microstructure and mechanical properties via instrumented nanoindentation. 


\section{Experimental procedure}

The $\mathrm{Mg} / \mathrm{Ti}$ multilayered thin films with equal layer thickness of $\mathrm{Mg}$ and $\mathrm{Ti}$ (from 2.5 to $100 \mathrm{~nm}$ ) were deposited onto $\mathrm{Si}$ (100) substrates at room temperature via magnetron sputtering technique, as described elsewhere [24]. The total thickness of each film was kept as $1.0 \mu \mathrm{m}$ by varying the number of layers. Afterwards, as-deposited $\mathrm{Mg} / \mathrm{Ti}$ specimens were subjected to annealing treatments at $50,100,150$ and $200{ }^{\circ} \mathrm{C}$, respectively. Since the constituents in $\mathrm{Mg} / \mathrm{Ti}$ multilayer system are reactive with oxygen and prone to get oxidized at elevated temperatures, we wrapped the specimens in $\mathrm{Al}$ foils before placing them into the Barnstead-Thermolyne Model FA 1500 furnace flowed with high-purity Argon gas. The annealing time was varied from 0.5 to 2.0 hours and the heating rate was controlled at $12 \mathrm{~K} / \mathrm{min}$. After the annealing treatment, the specimens were furnace-cooled to room temperature. The following X-ray diffraction results demonstrate the effectiveness of such a treatment in preventing the oxidation of $\mathrm{Mg} / \mathrm{Ti}$ multilayers.

Bruker AXS D8 Discover X-ray diffractometer with $\mathrm{Cu}-\mathrm{K}_{\alpha}$ radiation was used to examine the phases and crystallography of the annealed $\mathrm{Mg} / \mathrm{Ti}$ films. Their cross-sectional microstructures were inspected by transmission electron microscopy (TEM) and high resolution transmission electron microscopy (HRTEM) on the JEOL 2100 microscope operated at $200 \mathrm{kV}$. All the TEM samples in this study were cut, milled and finished by Focused Ion Beam (FIB) technique on an FEI Nova 600i dual beam FIB system (US Army Research Laboratory).

The mechanical properties of the annealed specimens were mainly characterized by hardness, which was measured on an Agilent NanoIndenter G200 equipped with a Berkovich diamond tip. We adopted the continuous stiffness method (CSM) proposed by Oliver and Pharr [25] in the nanoindentation tests. Considering the substrate effects [26], the maximum indenter 
penetration depth was set as $120 \mathrm{~nm}(\sim 10-15 \%$ of the total thickness for each film). At least ten indentation points were made on each annealed film.

\section{Results}

Fig. 1 shows the X-ray diffraction (XRD) patterns of $\mathrm{Mg} / \mathrm{Ti}$ multilayer nanofilms annealed at $200{ }^{\circ} \mathrm{C}$ for $2 \mathrm{~h}$. In consistency with the experimental results of as-deposited $\mathrm{Mg} / \mathrm{Ti}$ multilayers, both $\mathrm{Mg}$ and $\mathrm{Ti}$ nanolaminates are preferentially orientated along $c$-axis. However, annealing led to a slight shift of the major reflections, $\mathrm{Mg}$ (0002), Ti (1010) and Ti (0002), to larger angle $2 \theta$, as reflected by the difference in XRD pattern of the annealed multilayer and the as-deposited one (the dotted line in Fig. 1) at $h=100 \mathrm{~nm}$. It is suggested that the shrinkage of lattice parameter in $\mathrm{Mg}$ and $\mathrm{Ti}$ during annealing is associated with their different thermal expansion parameters from that of silicon substrate as well as relaxation of the lattice strain in the as-deposited films. We recorded the angle shift for each specimen and calculated the strain as small as $\sim 0.3 \%$. Therefore, with respect to the high strength of $\mathrm{Mg} / \mathrm{Ti}$ metallic multilayers [24], the stress introduced during annealing is quite small and could be negligible.

As illustrated by the satellite peaks situating symmetrically around the major reflections in Fig. $1, \mathrm{Mg} / \mathrm{Ti}$ multilayers retained the lamellar microstructure even upon annealing at $200{ }^{\circ} \mathrm{C}$. In addition, there is no characteristic peak of magnesia or titania (e.g. $\mathrm{MgO}(200)$ at $\sim 44^{\circ}$ and $\mathrm{TiO}_{2}(004)$ at $\left.\sim 37^{\circ}\right)$ detected from the XRD spectra, indicating that the constituents of annealed films are still $\mathrm{Mg}$ and Ti. It should be mentioned that the highest annealing temperature of $473 \mathrm{~K}$ has exceeded half of the melting point of pure $\mathrm{Mg}(473 \mathrm{~K}$ vs $923 \mathrm{~K})$. Such a high annealing temperature should be able to induce substantial atomic diffusion in Mg layers. 
To further evaluate the morphological stability of $\mathrm{Mg} / \mathrm{Ti}$ multilayers at elevated temperatures, the microstructure of annealed films was investigated via TEM. Fig. $2 \mathrm{a}$ is a typical bright-field micrograph illustrating the cross-sectional microstructure of $h=20 \mathrm{~nm} \mathrm{Mg} / \mathrm{Ti}$ multilayers after annealing at $200{ }^{\circ} \mathrm{C}$ for $2 \mathrm{hrs,}$, in which the interfaces are clearly still continuous. In other words, the individual Mg and Ti layers are intact, without any pinch-off or breakdown. At this layer thickness level, epitaxial growth pattern OR.1 (Mg $\{0002\} / / \mathrm{Ti}\{0002\})$ and nonepitaxial growth pattern OR.2 ( $\mathrm{Mg}\{0002\} / / \mathrm{Ti}\{0110\})$ were found to coexist in the asdeposited films [24]. Similarly, both of them have been identified in these annealed specimens. Fig. $2 b$ is the selected-area diffraction pattern (SADP) corresponding to Fig. 2a, showing the existence of OR.2.

Unlike the uniform lamellar structure in Fig. 2a for $h=20 \mathrm{~nm}$, the cross-sectional area of the annealed $h=2.5 \mathrm{~nm} \mathrm{Mg} / \mathrm{Ti}$ multilayers is characterized with discontinuous interfaces separated by columnar boundaries, as shown in Fig. 3a. The average columnar width is approximately $80 \mathrm{~nm}$. Columnar growth is very common in vapor-deposited films and is largely determined by the sputtering parameters. It has been reported in $\mathrm{Ag} / \mathrm{Cu}$ [27], $\mathrm{Ni} / \mathrm{Ru}[17], \mathrm{Cu} / \mathrm{Nb}$ [18], $\mathrm{Cu} / \mathrm{V}$ [28], $\mathrm{Fe} / \mathrm{Ti}$ [29] and other metallic multilayer nanofilms. In each column, $\mathrm{Mg}$ and $\mathrm{Ti}$ hold the epitaxial growth pattern, with a typical SADP shown in Fig. 3b. Our crystallographic investigation also demonstrates that the mis-orientation between adjacent columns is extremely small.

Noteworthy is a feature present at the bottom of Fig. 3a, where there is breakdown of constituent layers at columnar boundaries, which has been rarely seen in the $h=2.5 \mathrm{~nm} \mathrm{Mg} / \mathrm{Ti}$ multilayers in the as-deposited condition. The HRTEM image in Fig. 4a provides us a close-up view of the interrupted layers. It is evident that a great deal of lattice distortion occurs in the 
vicinity of layer breakdowns. However, the layer termination or grain spheroidization that is always found to accompany the heat treatments of immiscible multilayers has not been observed here. A representative area containing rearranged atoms (the yellow square in Fig. 4a) was selected and then enlarged in Fig. 4b. Apparently, the atomic configuration is different from the normal HCP lattice. The planar spacing $d_{1}$ and $d_{2}$ sketched out in Fig. $4 \mathrm{~b}$ were measured as $\sim 0.25$ and $0.30 \mathrm{~nm}$, respectively. Fig. $4 \mathrm{c}$ is the Fast Fourier Transformation (FFT) image of Fig. 4b, which is also distinct from that in Fig. 3b. In this regard, metastable phases are believed to evolve in the $h=2.5 \mathrm{~nm} \mathrm{Mg} / \mathrm{Ti}$ multilayers during annealing. Although the intermixing between constituents is not expected in $\mathrm{Mg} / \mathrm{Ti}$ multilayers, it is still difficult to discriminate $\mathrm{Ti}$ and $\mathrm{Mg}$ atoms located at the column boundaries since they have almost identical FFT images. Examination of the regions right above the yellow square in Fig. 4a reveals that $d_{2}$ shrinks to $\sim 0.28 \mathrm{~nm}$. Thus the region enclosed by the yellow square is more likely to be migrated $\mathrm{Mg}$ atoms. With concerns about the appearance of such an atomic rearrangement and its influence on the mechanical behavior of $\mathrm{Mg} / \mathrm{Ti}$ multilayer nanofilms, we will present a detailed discussion later.

The evolution of hardness as a function of annealing temperature for the $\mathrm{Mg} / \mathrm{Ti}$ multilayer nanofilms is plotted in Fig. 5. Given the annealing time up to 2 hours, no significant change of hardness is noted in the multilayers with $h \geq 5 \mathrm{~nm}$. However, the hardness of $h=2.5 \mathrm{~nm}$ $\mathrm{Mg} / \mathrm{Ti}$ multilayers exhibits a descending trend as the annealing temperature increases, eventually reaching the minimum of $\sim 3.30 \mathrm{GPa}$ at $200{ }^{\circ} \mathrm{C}$. According to the Tabor's law, the flow strength corresponding to the minimum hardness is roughly $1.22 \mathrm{GPa}$, which is still very impressive in the community of metallic multilayers. Additionally, the effect of annealing time on the hardness of $\mathrm{Mg} / \mathrm{Ti}$ multilayers is illustrated in Fig. 6. Similar to annealing temperature, the annealing time has limited impacts on the strength of $\mathrm{Mg} / \mathrm{Ti}$ multilayers when $h \geq 5 \mathrm{~nm}$. Holding at $200{ }^{\circ} \mathrm{C}$ for 2 
hrs brings about a remarkable drop in hardness of the $h=2.5 \mathrm{~nm} \mathrm{Mg} / \mathrm{Ti}$ films. This dependence of strength on the annealing time implies the occurrence of diffusion-related processes in $\mathrm{Mg} / \mathrm{Ti}$ multilayers at elevated temperatures.

\section{Discussion}

In what follows, we will attempt to provide some in-depth discussion with respect to the experimental results presented in the previous section. Our focus will be primarily on the microstructural stability and evolution of mechanical properties of the $\mathrm{Mg} / \mathrm{Ti}$ multilayer films when subjected to thermal annealing.

\subsection{Microstructural stability}

The experimental results presented above indicate the excellent microstructural and mechanical property stability of $\mathrm{Mg} / \mathrm{Ti}$ multilayer nanofilms with $h \geq 5 \mathrm{~nm}$ upon annealing at up to $200{ }^{\circ} \mathrm{C}$. Thermally induced changes on the lamellar microstructure and mechanical properties were mainly manifested in the annealed films with $h=2.5 \mathrm{~nm}$. Hence, the following discussions are primarily based on the microstructural evolution of $\mathrm{Mg} / \mathrm{Ti}$ multilayers at this length scale.

With regards to the lamellar microstructure, there are several instability mechanisms derived from the studies of eutectic and eutectoid composites (i.e. Ti/Al alloys), including direct cylinderization, edge spheroidization, boundary splitting, termination migration and so on [3032]. Our microstructural investigation on the annealed $\mathrm{Mg} / \mathrm{Ti}$ multilayers reveals the absence of granular morphology, suggesting the deterioration of lamellar structure at $h=2.5 \mathrm{~nm}$ largely results from the boundary thermal grooving. However, considering the fact that the boundaries could hardly be discerned in Mg and Ti individual layers except at column walls (Fig. 3a and Fig. 4a), the classic model, which describes the groove development at intersections of grain boundaries and phase interfaces, cannot be directly used to the $\mathrm{Mg} / \mathrm{Ti}$ multilayers. Here we 
propose a modified thermal grooving model to interpret the morphological instability of $\mathrm{Mg} / \mathrm{Ti}$ multilayers.

Fig. 7a schematically illustrates the microstructure of an as-deposited $\mathrm{Mg} / \mathrm{Ti}$ multilayer nanofilm. It is well known that the morphology of thin films is considerably sensitive to the deposition conditions such as deposition pressure and substrate temperature. Therefore, in spite of the prevalent continuity of $\mathrm{Mg}$ and $\mathrm{Ti}$ layers throughout the film, the appearance of tiny morphological perturbations (e.g. interfacial waviness) in $\mathrm{Mg} / \mathrm{Ti}$ multilayers is practically inevitable, which can be possibly attributed to the competition between instabilities arising from discrete atomic deposition and stabilizing influence of surface diffusion [33]. Due to the curved interface geometry where chemical potential gradient lies, the diffusive mass transportation associated with increasing temperature will intensify the grooving as shown in Fig. 7b. The tendency to relieve the stress caused by thermal strain and misfit strain might be another driving force for the deep grooves in the annealed $\mathrm{Mg} / \mathrm{Ti}$ multilayers. The schematic diagrams in Fig. $7 \mathrm{a}$ and Fig. $7 \mathrm{~b}$ basically elucidate the presence of thermal grooves in the preferentially grown multilayer nanofilms where grain boundaries are scarce.

Rather than the conspicuous layer recession in annealed $\mathrm{Cu} / \mathrm{Nb}$ multilayers [19], the atomic diffusion gives rise to a transition zone (enclosed by the red dotted lines in Fig. 7c) on the cross-sectional microstructure, in which $\mathrm{Mg}$ and $\mathrm{Ti}$ have a different atomic configuration from the HCP structure. As a matter of fact, both Mg and Ti have a strong propensity to phase transformation, particularly at high temperature, high pressure or other favorable conditions. For example, pure Ti experiences a natural transition from $\alpha$ phase (HCP structure) to $\beta$ phase (BCC structure) at approximately $1115 \mathrm{~K}$. Alloying with beta stabilizers, i.e. Mo, Ta, Fe and Co, is able to lower the transition temperature. Increasing strain was also observed to promote the $\alpha$-to- $\beta$ 
phase transition in a Ti alloy even at ambient temperature [34]. Nevertheless, the phase transition of $\mathrm{Mg}$ is more dependent on the pressure than on the temperature. The calculation results based on first-principles theory from Jona and Marcus revealed a martensitic transition of $\mathrm{Mg}$ from HCP structure to BCC structure at hydrostatic pressure lager than 500kbar [35]. Moreover, the metastable $\mathrm{BCC} \mathrm{Mg}$ were experimentally observed in the magnetron sputtered $\mathrm{Mg} / \mathrm{Nb}$ multilayers with individual layer thickness of $5 \mathrm{~nm}$, while subsequent density functional theory calculations demonstrated that the stabilization of BCC $\mathrm{Mg}$ deposited on BCC $\mathrm{Nb}$ substrate is analogous to the stabilization of $\mathrm{BCC} \mathrm{Mg}$ under high pressures because of the mechanical constraints imposed on $\mathrm{Mg}[36,37]$.

Although our observation shows that $\mathrm{Mg}$ lattice in the transition zone is no longer exclusively HCP structure, it is not a perfect BCC or FCC lattice either. The FFT image in Fig. $4 \mathrm{c}$ is analogous to the diffraction pattern of BCC crystals with [111] zone axis but still shows small discrepancies from it, which essentially originates from the difference between $d_{1}$ and $d_{2}$ in Fig. 4b. Therefore, the Mg at the columnar boundaries could be a metastable phase that possesses a transitional lattice structure from HCP to BCC. This speculation is also applicable for Ti. Since the transition zones only make up a small volume of the annealed $\mathrm{Mg} / \mathrm{Ti}$ nanofilms, the reflections of these metastable phases are too weak to be identified from the XRD patterns.

As mentioned previously, the degradation of lamellar structure was detected in the annealed $\mathrm{Mg} / \mathrm{Ti}$ films with $h=2.5 \mathrm{~nm}$, but is absent from other specimens. We believe this is indicative of the influence of individual layer thickness $h$ on the morphological stability in $\mathrm{Mg} / \mathrm{Ti}$ multilayer system. Such a size-dependent phenomenon could be explained from different perspectives. Firstly, the interfaces of $\mathrm{Mg} / \mathrm{Ti}$ multilayers with smaller $h$ is energetically less stable due to the high density of $\mathrm{Mg} / \mathrm{Ti}$ interfaces. The interfacial strain originating from the 
mismatch in elastic modulus and lattice parameter between constituents cannot be fully relaxed during quick alternating layer deposition. With more layers stacked together, the accumulative stress, which might be beneficial to the strength, makes the interface vulnerable to thermal exposure and in turn impairs the microstructural integrity upon annealing. Secondly, there might exist more structural imperfections at interfaces of the multilayers with smaller $h$. An early study about the columnar growth of multilayers from Czigány and Radnóczi has pointed out that during low temperature depositions the interface wavelength of waviness (equals column width) is nearly proportional to the individual layer thickness at nanoscale $h$ [38]. These surface irregularities potentially act as initial sites of atomic rearrangements as described above. Thirdly, boundary splitting is easier to take place at smaller $h$ because the diffusion distance is shortened. A critical $d / h$ ratio ( $d$ denotes the grain size) correlated to the grain-boundary energy of layer constituents was even proposed by Josell et al., below which the layer pinch-off is restricted [39]. Unfortunately, owing to the ambiguous grain boundaries in $\mathrm{Mg} / \mathrm{Ti}$ multilayers, it is almost impossible to determine the average value of $d$. Thereby, we did not attempt to quantitatively derive this critical ratio for $\mathrm{Mg} / \mathrm{Ti}$ multilayer system in this study.

\subsection{Mechanical stability}

To a large extent, the mechanical stability of metallic multilayers is controlled by their morphological stability. In the literature, grain growth and layer coarsening are two major factors that impact adversely on the mechanical properties at elevated temperatures. For example, Misra et al. found that the decrease of hardness $(\sim 0.3 \mathrm{GPa})$ in $h=75 \mathrm{~nm} \mathrm{Cu} / \mathrm{Nb}$ multilayers during a short-time anneal at $700{ }^{\circ} \mathrm{C}$ was primarily caused by the apparent in-plane grain growth from $\sim 75 \mathrm{~nm}$ to $\sim 200 \mathrm{~nm}$. As for the $h=15 \mathrm{~nm} \mathrm{Cu} / \mathrm{Nb}$ multilayers, a dramatic drop of hardness by a factor of two was noticed when the annealing temperature approached $600{ }^{\circ} \mathrm{C}$, at which 
spheroidization of the lamellar microstructure began [19]. The detrimental impacts of layer spheroidization on the mechanical integrity were also reported in $\mathrm{Ni} / \mathrm{Ru}\left(\right.$ at $\left.600{ }^{\circ} \mathrm{C}\right)$ [17] and $\mathrm{Cu} / \mathrm{Ag}$ multilayers (at $\left.149^{\circ} \mathrm{C}\right)[16]$.

For our $h \geq 5 \mathrm{~nm} \mathrm{Mg} / \mathrm{Ti}$ multilayer nanofilms following thermal annealing, the nearly unchanged hardness as shown in Fig. 5 and Fig. 6 is fundamentally connected with their impressive resistance to the deterioration of lamellar microstructure. The decrease of hardness in annealed $\mathrm{Mg} / \mathrm{Ti}$ multilayer specimens with the smallest $h(h=2.5 \mathrm{~nm})$ should account for the thermally induced transition zones since neither grain growth nor layer coarsening has been observed. It is suggested that, the appearance of transition zones with rearranged atoms disrupted the continuous interfaces and thus weakened their impeding effects toward the Orowan-type dislocation sliding as well as the subsequent dislocation transmission. On this basis, a further decrease of strength is predicted if the annealing temperature or annealing time increases.

\section{Summary and Concluding Remarks}

A variety of thermal anneals were performed on the magnetron sputtered $\mathrm{Mg} / \mathrm{Ti}$ multilayer nanofilms to evaluate their thermal and mechanical stability. These HCP-based multilayers possess impressive capability of maintaining the lamellar microstructure as well as high-level hardness up to $200{ }^{\circ} \mathrm{C}$ when the individual layer thickness $h$ is no less than $5 \mathrm{~nm}$. In the annealed $\mathrm{Mg} / \mathrm{Ti}$ multilayers with $h=2.5 \mathrm{~nm}$, transition zones characterized with atomic arrangement from $\mathrm{HCP}$ to $\mathrm{BCC}$ lattice appear at the columnar boundaries. Owing to the interruption of continuous interfaces, the hardness of $\mathrm{Mg} / \mathrm{Ti}$ multilayers at this length scale of $h$ exhibits a descending trend with the annealing temperature and reaches the minimum of $3.3 \mathrm{GPa}$ after annealing at $200{ }^{\circ} \mathrm{C}$ for $2 \mathrm{hrs}$.

\section{Acknowledgement}


Y.Y. Lu are grateful for the financial support from the Education Ministry of the People's Republic of China during her pursuit for her $\mathrm{PhD}$ at The University of North Carolina at Charlotte. This research work is supported by US Army Research Laboratory under Contract No.

W911QX-08-C-0073. S. N. Yarmolenko has been supported by National Science Foundation through ERC.

\section{Reference}

[1] J.S. Koehler, Physical Review B, 2 (1970) 547-551.

[2] P.M. Anderson, C. Li, Nanostruct. Mater., 5 (1995) 349-362.

[3] R.G. Hoagland, R.J. Kurtz, C.H. Henager, Scripta Materialia, 50 (2004) 775-779.

[4] A. Misra, H. Kung, J.D. Embury, Scripta Materialia, 50 (2004) 707-710.

[5] A. Misra, J.P. Hirth, R.G. Hoagland, Acta Materialia, 53 (2005) 4817-4824.

[6] Y.M. Wang, J. Li, A.V. Hamza, T.W. Barbee, PNAS, 104 (2007) 11155-11160.

[7] J.Y. Zhang, X. Zhang, R.H. Wang, S.Y. Lei, P. Zhang, J.J. Niu, G. Liu, G.J. Zhang, J. Sun, Acta Materialia, 59 (2011) 7368-7379.

[8] T.P. Weihs, T.W. Barbee, M.A. Wall, Acta Materialia, 45 (1997) 2307-2315.

[9] H.J. Lee, K.W. Kwon, C. Ryu, R. Sinclair, Acta Materialia, 47 (1999) 3965-3975.

[10] Z. Jiang, X. Jiang, W. Liu, Z. Wu, Journal of Applied Physics, 65 (1989) 196-200.

[11] D. Beke, G. Langer, M. Kis-Varga, A. Dudas, P. Nemes, L. Daróczi, G. Kerekes, Z. Erdélyi, Vacuum, 50 (1998) 373-383.

[12] B. Kucharska, E. KuLej, M. Gwozdzik, Archives of Metallurgy and Materials, 57 (2012) 671-677.

[13] B. Kucharska, E. Kulej, A. Wrobel, Optica Applicata, 42 (2012).

[14] A. Dudás, G. Langer, D. Beke, M. Kis-Varga, L. Daróczi, Z. Erdélyi, Journal of Applied Physics, 86 (1999) 2008-2013.

[15] M. Bobeth, M. Hecker, W. Pompe, C. Schneider, J. Thomas, A. Ullrich, K. Wetzig, Zeitschrift für Metallkunde, 92 (2001) 810-819.

[16] Q. Zhai, D. Kongq, A. Morrone, F. Ebrahimi, in: Materials Research Society Symposium Proceedings, Cambridge Univ Press, 1997, pp. 489-494.

[17] S. Wen, R. Zong, F. Zeng, Y. Gu, Y. Gao, F. Pan, Surface and Coatings Technology, 202 (2008) 2040-2046.

[18] A. Misra, R. Hoagland, H. Kungł, Philosophical Magazine, 84 (2004) 1021-1028.

[19] A. Misra, R. Hoagland, J. Mater. Res., 20 (2005) 2046-2054.

[20] S.S. Grabchikov, L.B. Sosnovskaya, K.I. Yanushkevich, Journal of magnetism and magnetic materials, 308 (2007) 101-107.

[21] L. Smardz, J. Alloy. Compd., 395 (2005) 17-22.

[22] A. Chaiken, R. Michel, M. Wall, Physical Review B, 53 (1996) 5518.

[23] Y. Kaneko, H. Sakakibara, S. Hashimoto, Journal of Materials Science, 43 (2008) 39313937. 
[24] Y. Lu, R. Kotoka, J. Ligda, B. Cao, S. Yarmolenko, B. Schuster, Q. Wei, Acta Materialia, 63 (2014) 216-231.

[25] W.C. Oliver, G.M. Pharr, Journal of Materials research, 7 (1992) 1564-1583.

[26] R. Saha, W.D. Nix, Acta Materialia, 50 (2002) 23-38.

[27] Z. Czigány, I. Kovacs, G. Radnoczi, Thin Solid Films, 317 (1998) 266-269.

[28] E.G. Fu, N. Li, A. Misra, R.G. Hoagland, H. Wang, X. Zhang, Materials Science and Engineering a-Structural Materials Properties Microstructure and Processing, 493 (2008) 283287.

[29] W. Wang, L.S. Wen, J. Mater. Sci. Technol., 17 (2001) 521-524.

[30] G. Sharma, R. Ramanujan, G. Tiwari, Acta Materialia, 48 (2000) 875-889.

[31] T. Courtney, J. Kampe, Acta Metallurgica, 37 (1989) 1747-1758.

[32] J. Kampe, T. Courtney, Y. Leng, Acta Metallurgica, 37 (1989) 1735-1745.

[33] A. Mazor, D. Srolovitz, P. Hagan, Bukiet, BG, PHYSICAL REVIEW LETTERS, 60 (1988) 424.

[34] Y. Han, H. Zhuang, J. Lu, J. Mater. Res., 24 (2009) 3439-3445.

[35] F. Jona, P. Marcus, Journal of Physics: Condensed Matter, 15 (2003) 7727.

[36] B. Ham, X. Zhang, Mater. Sci. Eng. A-Struct. Mater. Prop. Microstruct. Process., 528 (2011) 2028-2033.

[37] A. Junkaew, B. Ham, X. Zhang, A. Talapatra, R. Arróyave, Materials Research Letters, 1 (2013) 161-167.

[38] Z. Czigány, G. Radnóczi, Thin Solid Films, 347 (1999) 133-145.

[39] D. Josell, F. Spaepen, MRS Bulletin, 24 (1999) 39-43. 


\section{Figure Captions:}

Fig. 1. XRD patterns of $\mathrm{Mg} / \mathrm{Ti}$ multilayer nanofilms annealed at $200{ }^{\circ} \mathrm{C}$ for 2 hours. They are very similar to the XRD results of the as-deposited multilayer films, except for a small angle shift of major reflections [24]. For detailed comparison, the XRD pattern of as-deposited $\mathrm{Mg} / \mathrm{Ti}$ multilayer with $h=100 \mathrm{~nm}$ is illustrated by the dotted line.

Fig. 2. (a) The bright-field TEM micrograph illustrating the cross-sectional microstructure of $h=20 \mathrm{~nm} \mathrm{Mg} / \mathrm{Ti}$ multilayers upon annealing at $200{ }^{\circ} \mathrm{C}$ for $2 \mathrm{hrs}$, with the corresponding selected area diffraction pattern (SADP) displayed in (b). Both the TEM image and the SADP indicate negligible change in the microstructure of the annealed specimen. The same orientation relationship between $\mathrm{Ti}$ and $\mathrm{Mg}$ phases is detected as in the as-deposited specimen [24].

Fig. 3. (a) The bright-field TEM micrograph illustrating the cross-sectional microstructure of $h=2.5 \mathrm{~nm} \mathrm{Mg} / \mathrm{Ti}$ multilayered nanofilm annealed at $200{ }^{\circ} \mathrm{C}$ for $2 \mathrm{hrs}$. $\mathrm{Mg}$ layers are in bright while Ti layers are in dark. (b) A typical SADP within the column illustrating the epitaxial growth between $\mathrm{Mg}$ and Ti. Compared to the as-deposited specimen [24], the significant change associated with thermal annealing is the emergence of the columnar structure.

Fig. 4. (a) An HRTEM image illustrating the breakdown of individual layers at column boundaries in the annealed Mg/Ti multilayers with $h=2.5 \mathrm{~nm}$. (b) The enlarged HRTEM image shows the detailed atomic rearrangement, with the correspoding FFT image in (c). At the column boundaries, body-centered cubic regions can be detected. See text for detailed discussion.

Fig. 5. The hardness of $\mathrm{Mg} / \mathrm{Ti}$ metallic multilayers annealed at various annealing temperatures for $2 \mathrm{hrs}$. It is observed that except for the $h=2.5 \mathrm{~nm}$ specimen, all other specimens exhibit outstanding thermal and mechanical stability. This is particularly surprising as the highest annealing temperature is more than half the melting point of $\mathrm{Mg}$.

Fig. 6. The hardness of $\mathrm{Mg}$ /Ti metallic multilayers annealed at $200^{\circ} \mathrm{C}$ for various annealing time periods. Again, except for the $h=2.5 \mathrm{~nm}$ specimen, most specimens possess extraordinary thermal and mechanical stability upon annealing at this temperature, which is more than half the melting point of $\mathrm{Mg}$.

Fig. 7. Schematic diagrams of the morphological instability in $\mathrm{Mg} / \mathrm{Ti}$ multilayers. This analysis applies to very small $h$ values. 


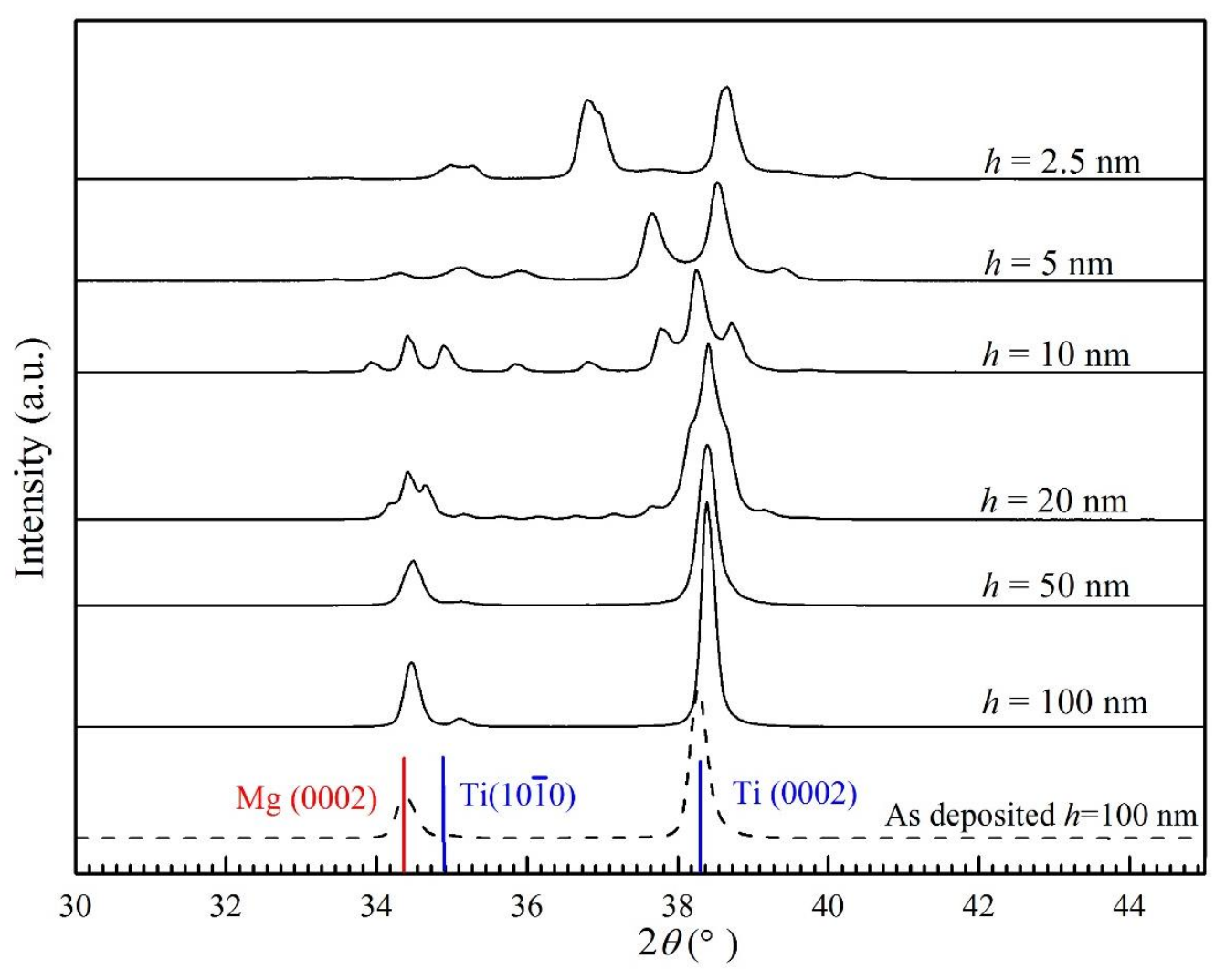

Fig. 1. XRD patterns of $\mathrm{Mg} / \mathrm{Ti}$ multilayer nanofilms annealed at $200{ }^{\circ} \mathrm{C}$ for 2 hours. They are very similar to the XRD results of the as-deposited multilayer films, except for a small angle shift of major reflections [24]. For comparison, the XRD pattern of as-deposited $\mathrm{Mg} / \mathrm{Ti}$ multilayer with $h=100 \mathrm{~nm}$ is shown by the dotted line. 


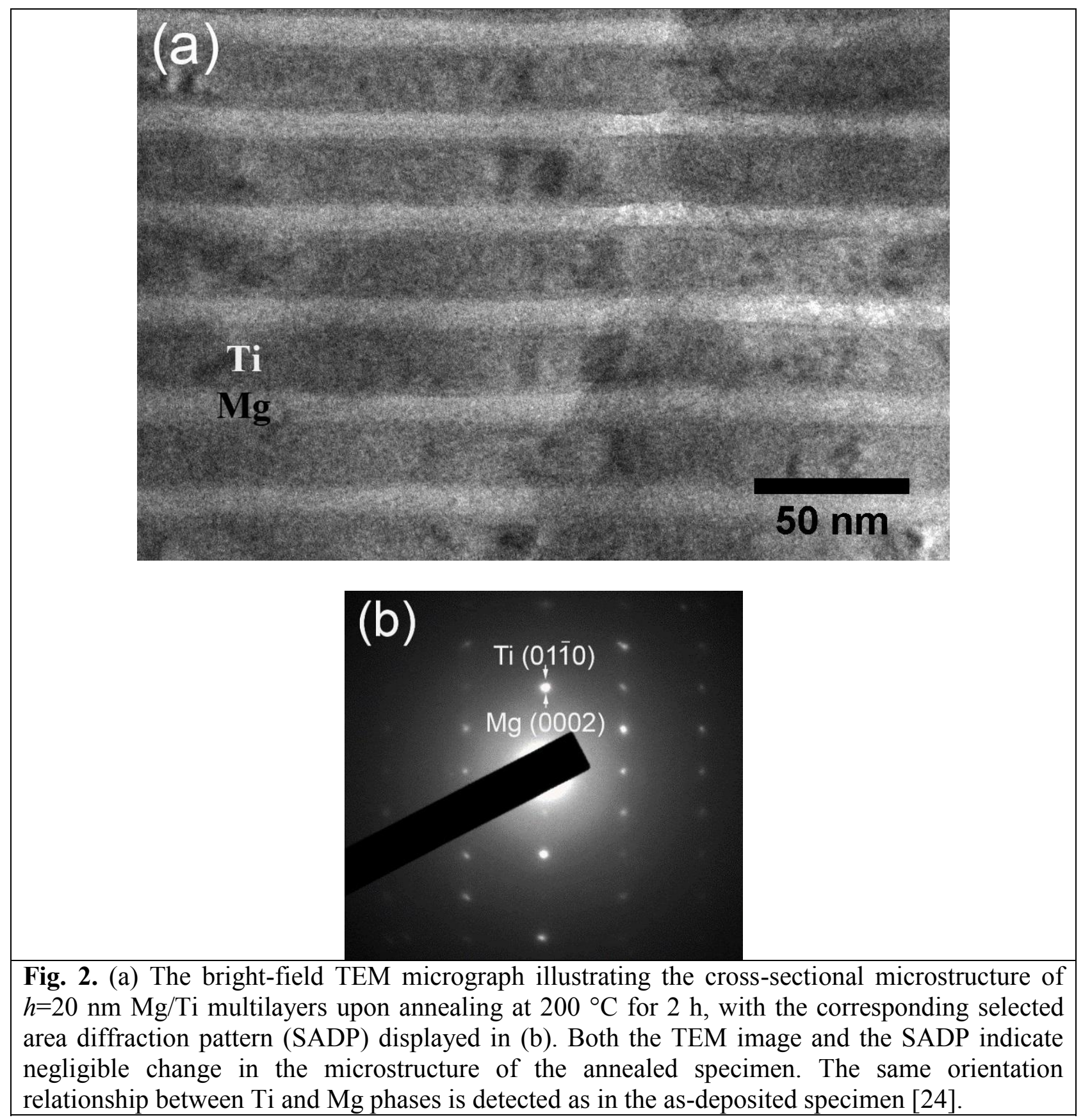




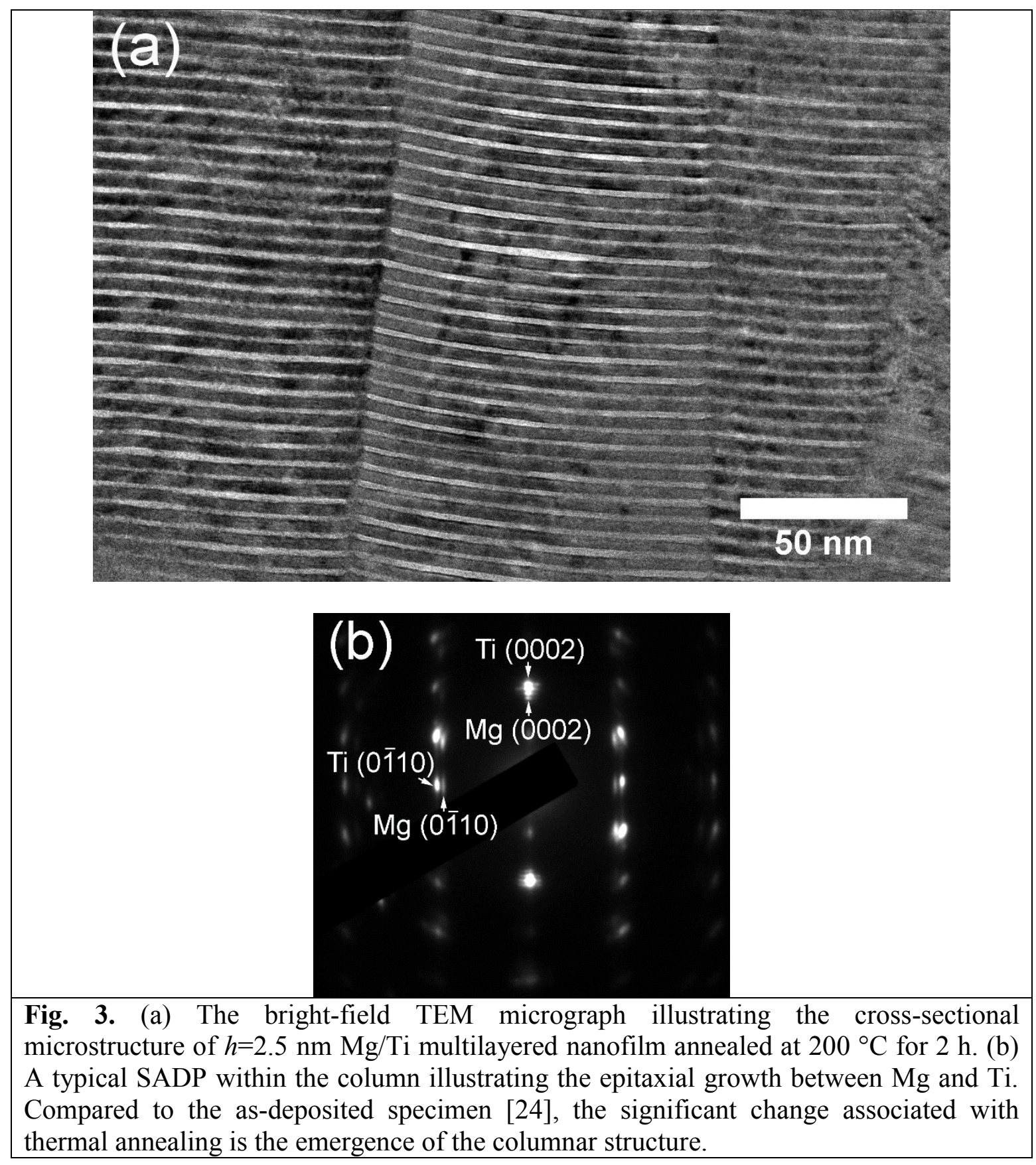




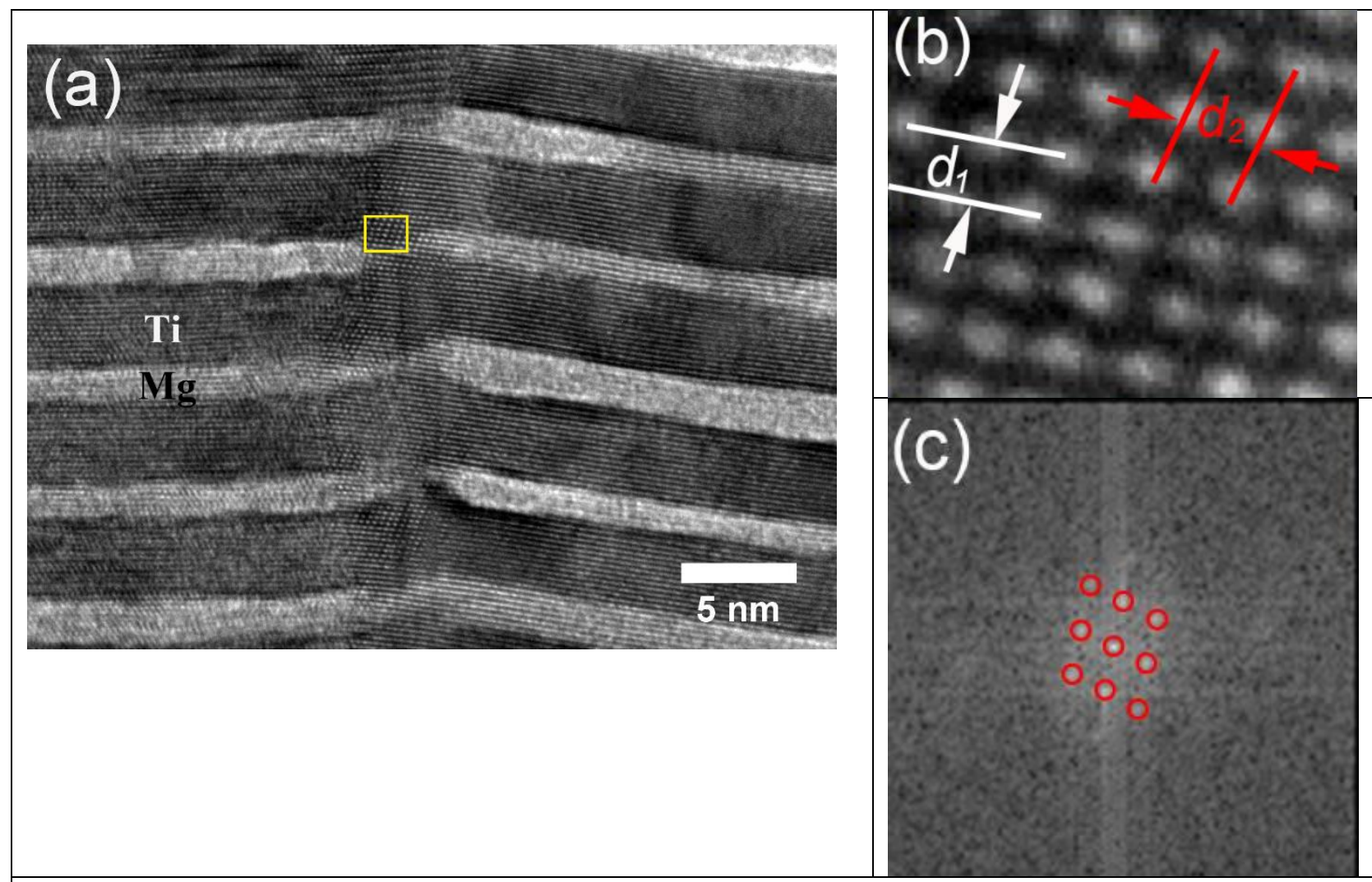

Fig. 4. (a) An HRTEM image illustrating the breakdown of individual layers at column boundaries in the annealed $\mathrm{Mg} / \mathrm{Ti}$ multilayers with $h=2.5 \mathrm{~nm}$. (b) The enlarged HRTEM image shows the detailed atomic rearrangement, with the correspoding FFT image in (c). At the column boundaries, body-centered cubic regions can be detected. See text for detailed discussion. 


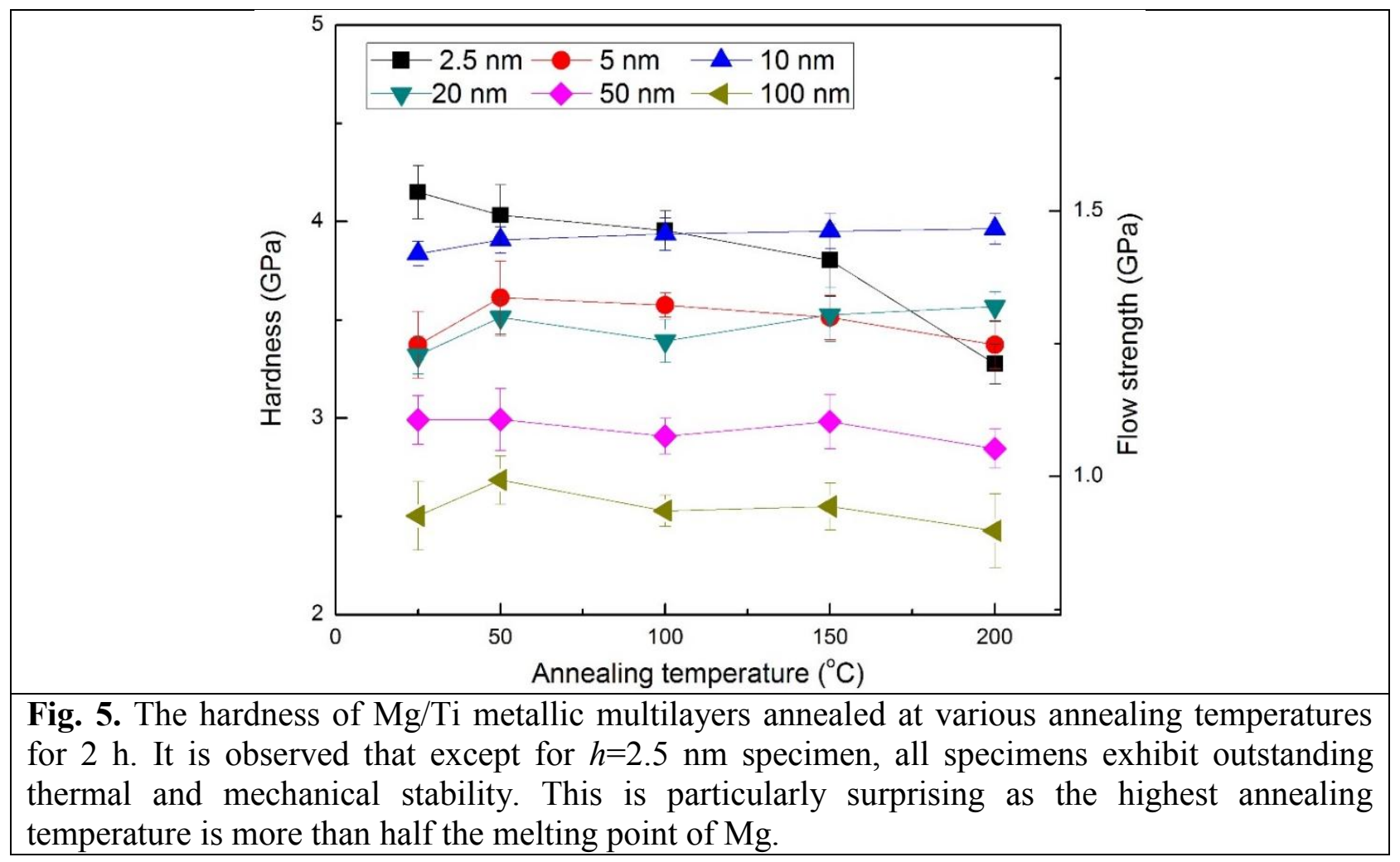




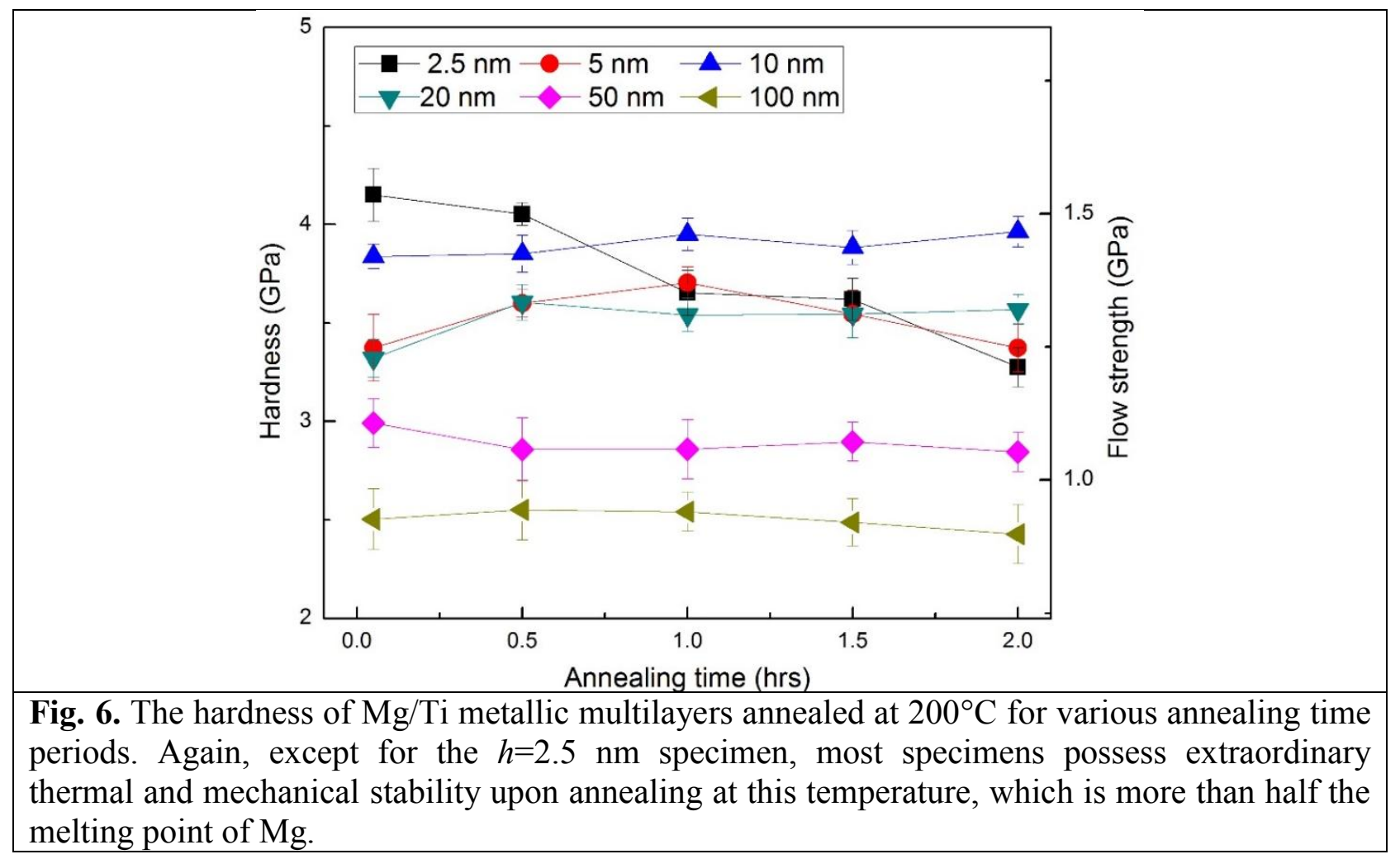


(a)

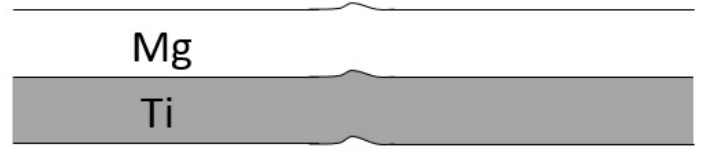

$\mathrm{Mg}$

(b)

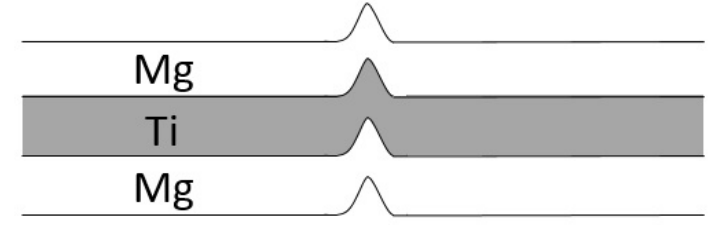

(c)

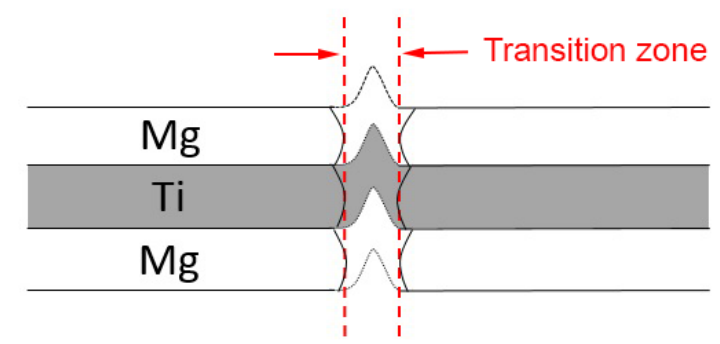

Fig. 7. Schematic diagrams of the morphological instability in $\mathrm{Mg} / \mathrm{Ti}$ multilayers. This analysis applied to very small $h$ values. 